74 巻 747 号 (2008-11)

\title{
テーラーメード型積層圧電アクチュエータの支持部解析と評価*
}

\author{
当田直 哉*1, 中島 正 博*2 \\ 新井史 ${ }^{* 3}$, 福田敏 男*4
}

\section{Analysis and Evaluation of Support for Tailor-Made Multilayer Piezoelectric Actuator}

\author{
Naoya TODA, Masahiro NAKAJIMA*5, \\ Fumihito ARAI and Toshio FUKUDA \\ *5 Department of Micro-Nano Systems Engineering, Nagoya University, \\ Furo-cho, Chikusa-ku, Nagoya-shi, Aichi, 464-8603 Japan
}

\begin{abstract}
We have been proposed the tailor-made multilayer piezoelectric actuator (TAMPA) with large displacement and large force. TAMPA has the layered structure of two bimorph-type piezoelectric elements combined by both ends supported. Therefore, the performance of TAMPA is affected by the shape and the stiffness of support. It is necessary to design the optimum structure of support of TAMPA. This paper proposes four-point supported structure because of the plate shape of bimorphtype piezoelectric elements. The effect of the shape of supports is estimated through finite element analysis of TAMPA constructed by four-point support of varied sizes. The TAMPA having the optimum structure determined from estimation result is produced and its performance is evaluated. For production, the mold made by rapid prototyping is utilized. It is possible to produce the support which had arbitrary shape by using this mold.
\end{abstract}

Key Words: Actuator, Piezo-Element, Laminated Construction, Tailor-Made, Support Shape

\section{1. 緒 言}

圧電アクチュエータは, 小型でありながら優れた発生 力, 高精度, 高応答性を有するため, 自動車部品, 家電 製品, マイクロ・ナノデバイス等の様々な部品へ応用さ れている(1)(2). しかしながら, 圧電素子は変形量が小さ いため, 変位を増幅させるための機構がこれまで多く提 案されている. 外部機構を用いたものとしては, 変位拡 大機構付き積層圧電アクチュエータ (3) (4), Moonie $^{(5)}$,

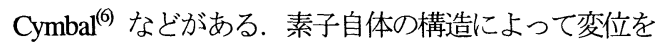
増幅させているものとしては, バイモルプ, Rainbow ${ }^{(8)}$, Thunder ${ }^{(9)}$ などがある. これらの手法の問題点として, 外部機構を用いたアクチュエータは機械損失を考慮す る必要があり,また小型化, 低コスト化が難しい. また, 素子の構造によって変位を得ているアクチュエータは 比較的小型化が容易であるが, 発生力を十分に得ること が難しいといった事が挙げられる.

そこで Ervin らは，これらの要件を満たすために Recurve actuator を提案した ${ }^{(10)(11)}$. Recurve actuator は, 反

* 原稿受付 2008 年 3 月 6 日.

*1 名古屋大学大学院工学研究科 (事 464-8603 名古屋市千種区 不老町).

*2 正員, 名古屋大学大学院工学研究科.

*3 正員, フェロー, 東北大学大学院工学研究科(画 980-8579 仙 台市青葉区荒巻字青葉 6-6)

*4 正員, フェロー, 名古屋大学大学院工学研究科.

E-mail : nakajima@mein.nagoya-u.ac.jp

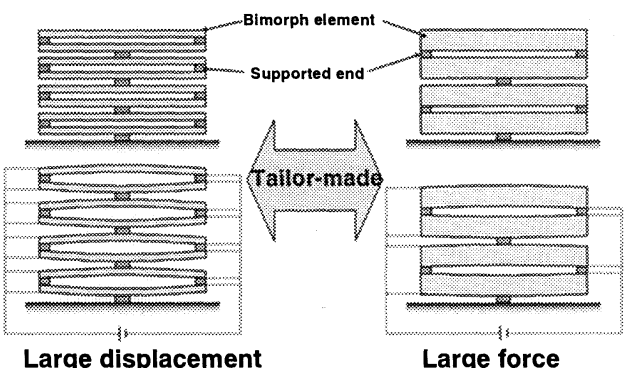

Fig. 1 Structure of Tailor-made Multilayer Piezoelectric Actuator (TAMPA)

曲するように分極されたバイモルフ型圧電素子からな る片持ちはりである. 反曲するように変形寸るため, 素 子の先端は平行を保ったまま上下させることができ, 効 率良くアレイ化することができる. Envin らは Recurve actuator を並列，または直列にアレイ化し，任意の変位 と力を得ている.

Recurve actuator では素子を反曲させるため, 目的の方 向とは反対向きの変形が含まれている.つまり, 本来の バイモルフ型圧電素子の持つ変形を犠牲にしているこ とになる. 我々は, 2 枚のバイモルフ型圧電素子を両端 支持で組み合水せ，それを積層することにより，変位と 力を両立させる積層圧電アクチュエータを提案した (12) 
(13). バイモルフ型圧電素子を片持ちはりから両端支持に することで, 変位は 4 分の 1 になるが力は 4 倍となる. また, 本アクチュエータは, 全体のサイズが同じでもバ イモルフ型圧電素子のサイズを調節することにより, 変 位と力のバランスを広範囲に変更可能なテーラーメー ドアクチュエータである（図1）。本論文では，本アク チュエータを TAMPA (Tailor-made Multilayer Piezoelectric Actuator）と呼ぶ.

TAMPA はバイモルフ型圧電素子を両端支持で組み 合わせた構造をしているため, その性能は, 支持部分の 形状や強度に大きく影響を受ける. よって支持部分の最 適構造を設計する必要がある. しかしこれまで, バイモ ルフ型圧電素子を積層した構造において, 支持構造がア クチュエータ性能に与える影響に関する研究はほとん どなされていない. 本論文ではまず, 支持形状がアクチ ユエータ性能に与える影響を有限要素解析により評価 し，その解析結果より，最適な支持構造を決定する. そ して決定された最適構造設計に基づいて TAMPA を作 製し評価を行う。

\section{TAMPA の概要}

両端支持されたバイモルフ型圧電素子は, 片持ちはり に比べて変位は4分の1になるが力は4倍になる すなわち, バイルフ型圧電素子を用いて力を得るため には，両端支持の方が有効である．このことから，

TAMPA は, バイルフ型圧電素子を中央支持と両端支 持を繰り返し積層した構造をしている.

TAMPAの製作プロセスを図 2 に示す. まず，土台上 に導電性テープを張り付ける（図 2-a）。次に，バイモ ルフ型圧電素子をその導電性テープ上に張り付ける (困 2-b) . 次に, 2 つ導電性テープをそのバイモルフ型圧 電素子上の両端に張り付ける（図2-c）. 次に, バイモ ルフ型圧電素子をその 2 つ導電性テープ上に張り付 ける（図2-d）。このプロセスを繰り返すことにより任 意の積層数の TAMPAを作製する（図3）。バイモルフ 型圧電素子はシリーズ型であり，素子同士が向かい合っ た面は同じ電位をとる. そのため, 導電性テープを用い ることで配線がシンプルになる.

3 種類のプロトタイプの諸特性を表 1 に示す. それぞ れのプロトタイプは，全体のサイズが約 $10 \times 10 \times 10 \mathrm{~mm}$ となるように設計されている. 入力電界はすべて 225 $\mathrm{V} / \mathrm{mm}$ である. 表 1 より, 全体のサイズが同様でも変位 と力のバランスが異なるアクチュエータが実現できて いることが分かる.

\section{3. 有限要素解析を用いた最適構造設計}
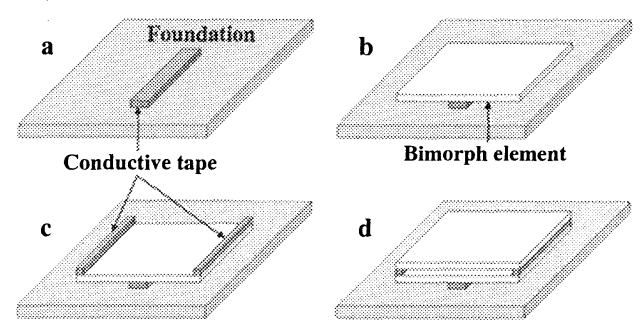

Fig. 2 Fabrication process of TAMPA

(a)
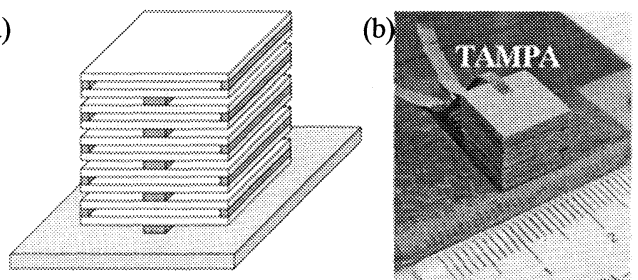

Fig. 3 Overview of produced TAMPA: (a) schematic figure, (b) photograph

Table 1 Characteristics of TAMPA

\begin{tabular}{|c|c|c|c|c|}
\hline \multicolumn{2}{|c|}{ Prototype } & 1 & 2 & 3 \\
\hline $\begin{array}{c}\text { Thickness of } \\
\text { bimorph } \\
\text { element }\end{array}$ & {$[\mu \mathrm{m}]$} & 200 & 400 & 800 \\
\hline $\begin{array}{c}\begin{array}{c}\text { Number of } \\
\text { layer }\end{array} \\
\end{array}$ & & 24 & 16 & 10 \\
\hline Size & {$\left[\mathrm{mm}^{3}\right]$} & $10 \times 10 \times 8.0$ & $10 \times 10 \times 8.5$ & $10 \times 10 \times 9.5$ \\
\hline $\begin{array}{c}\text { Free } \\
\text { displacement }\end{array}$ & {$[\mu \mathrm{m}]$} & 260 & 84 & 29 \\
\hline $\begin{array}{l}\text { Maximum } \\
\text { force }\end{array}$ & {$[N]$} & 0.28 & 0.89 & 2.1 \\
\hline $\begin{array}{l}\text { Resonance } \\
\text { frequency }\end{array}$ & {$[\mathrm{Hz}]$} & 150 & 500 & 1500 \\
\hline
\end{tabular}

Table 2 Physical properties of piezoelectric element and support

\begin{tabular}{clcc}
\hline & & $\begin{array}{c}\text { Piezo } \\
\text { element }\end{array}$ & Support \\
\hline Density & $\rho[\mathrm{kg} / \mathrm{m}]$ & 7400 & 7500 \\
Piezoelectric constant & $\mathrm{d}_{31}[\mathrm{pm} / \mathrm{V}]$ & 224 & - \\
Poisson's ratio & $v$ & 0.31 & 0.3 \\
Young's modulus & $\mathrm{Y}[\mathrm{GPa}]$ & 60 & 0.05 \\
\hline
\end{tabular}

従来のTAMPAはバイモルフ型圧電素子をはりと して設計されている(12),(13). そのためバイモルフ型圧 電素子が両端の 2 辺を支持した構造で作製されてい る.しかし，実際のバイモルフ型圧電素子は板状で あり，変形は長さ方向のみではなく幅方向にも起こ っている. そのため板状のバイモルフ型圧電素子の 支持は，角の 4 点支持が最適である.この場合， TAMPA は板の中心支持と 4 点支持を繰り返し積層 した構造となる. 以下, 4 点支持を適用した TAMPA の性能を有限要素解析により評価し, 最適構造を設 


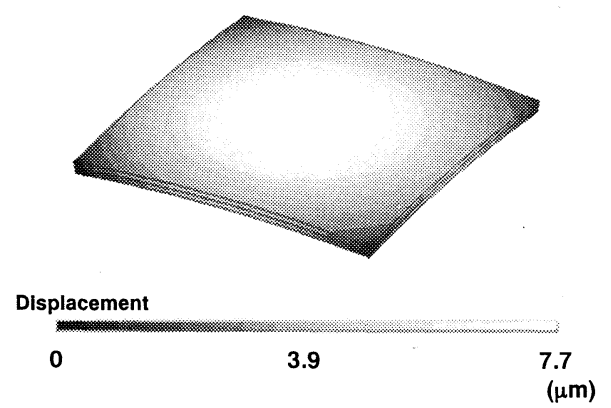

Fig. 4 Deformed configuration and contour map of bimorph piezoelectric element

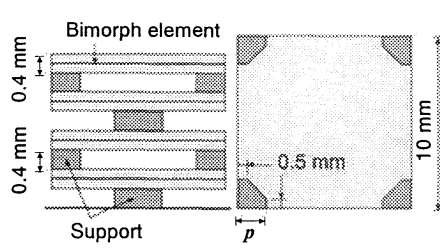

(a) (b)

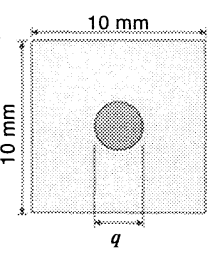

(c)
Fig. 5 Analytical model of four-supported TAMPA:

(a) front view, (b) cross-section of four-support, (c) cross-section of center support

計する. 有限要素解析には ANSYS 11.0 (ANSYS Inc.) )用いた. 圧電素子と支持部の物性を表 2 に示 す. 要素タイプは, 三次元ソリッド要素として, 圧 電素子及び支持材に四面体要素を用いた.

まず，支持部の基本的な形状を決定する. 図 4 に $10 \times 10 \mathrm{~mm}$ の正方形で，厚さ $0.4 \mathrm{~mm}$ のバイモルフ 型圧電素子の変形形状および等変位線を示寸 (総要 素数 : 1350, 総節点数：1792）. 素子はシリーズ型 であり, 入力電界は $225 \mathrm{~V} / \mathrm{mm}$ である. 図より, 横 方向だけでなく縦方向にも変形が起こり, 最も変位 が得られるのは板の中心部分であることが分かる。

また，等変位線から，中心は円形，4 隅はほぼ三角 形に等変位している. したがって，中心支持部は円 形，4点支持部は三角形が適しているといえる.

次に，それぞれの支持部がどのようにアクチュエ 一タの性能に影響するのかを解析する. 解析モデル は厚さ $0.4 \mathrm{~mm}$ のバイモルフ型圧電素子が 4 層の TAMPA とした（図 5 (a)）。支持部の厚みは, 実際 に作製することの容易さから $0.4 \mathrm{~mm}$ とした. 4 点支 持部は，実際に作製することを考慮して鋭角部分を $0.5 \mathrm{~mm}$ 切り落とした形状とした（図 5(b)). 中心支 持部は円形である（図 5 (c)）。解析は，4 点支持部 の大きさ $p$ が $0.5 \mathrm{~mm}, 1.0 \mathrm{~mm}, 1.5 \mathrm{~mm}, 2.0 \mathrm{~mm}$, 中 心支持部の直径 $q$ が $2.0 \mathrm{~mm}, 3.0 \mathrm{~mm}, 4.0 \mathrm{~mm}, 5.0 \mathrm{~mm}$ の 16 パターンについて行った. $0.5 \mathrm{~mm}$ の 4 点支持 部のみ正方形である. (a)

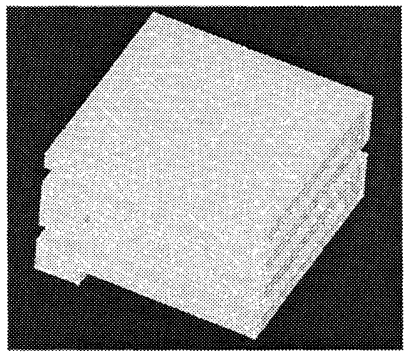

(b)

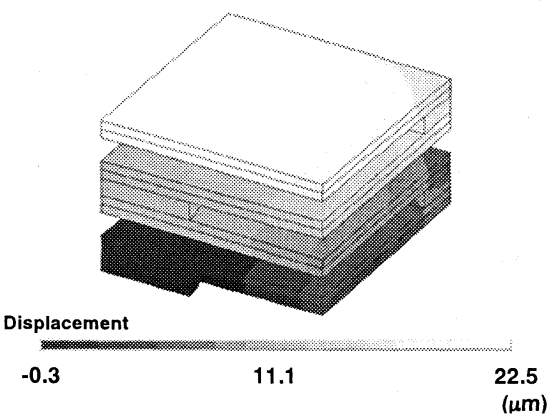

(c)

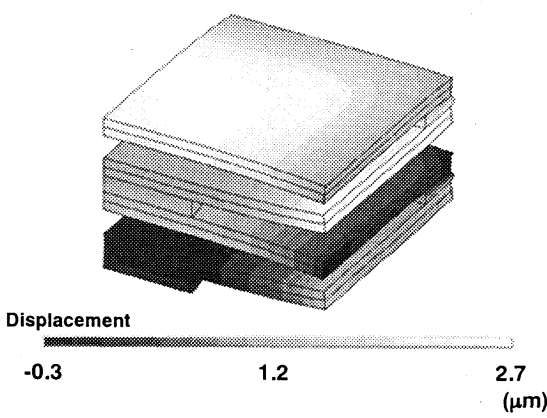

Fig. 6 Deformed configurations and contour map for a quarter of four-supported TAMPA (4 layered): (a) Mesh division map, (b) Free deflection, (c) $0.8 \mathrm{~N}$ loaded at center of top layer

例として, $p=1.0 \mathrm{~mm}, q=4.0 \mathrm{~mm}$ の場合の解析結 果を図 6 に示す.図 6(a)はメッシュ分割図を示す(総 要素数 : 11803, 総節点数 : 19886).アアクュエー 夕の対称性から 4 分の 1 部分のみ示している. 図6(b) は荷重なし, 図 6(c)はアクチュエー夕最上部の中心 に $0.8 \mathrm{~N}$ の荷重を加えた状態の変形図である. ただ し, 図(c)は図 6 (b)に対して, 変形量の倍率として, 約 8.3 倍拡大して表示している.

これらの解析から得られた最上部中心の自由変位 とブロッキングフォースの值を用いてアクエータ性 能を評価，比較する，評価のために，アクチュエー 夕のなす仕事 $W$ が自由変位とブロッキングフォー スの積で表されると定義する(10).ここでまず，比較 を簡単にするために, 自由変位 $D$ とブロッキングフ 
Table 3 Analytical results of four-supported TAMPA (4 layered)

\begin{tabular}{|c|c|c|c|c|c|}
\hline 9 mann & & $0.5 \mathrm{~mm}$ & $1.0 \mathrm{~mm}$ & $1.5 \mathrm{~mm}$ & $2.0 \mathrm{~mm}$ \\
\hline \multirow{3}{*}{$2.0 \mathrm{~mm}$} & $D^{*}$ & 0.89 & 0.78 & 0.67 & 0.55 \\
\hline & $F^{*}$ & 0.73 & 0.94 & 1.00 & 1.00 \\
\hline & $w^{*}$ & 0.65 & 0.74 & 0.67 & 0.55 \\
\hline \multirow{3}{*}{$3.0 \mathrm{~mm}$} & $D^{*}$ & 0.87 & 0.77 & 0.65 & 0.53 \\
\hline & $F^{*}$ & 0.77 & 1.02 & 1.11 & 1.15 \\
\hline & $W^{*}$ & 0.67 & 0.78 & 0.73 & 0.61 \\
\hline \multirow{3}{*}{$4.0 \mathrm{~mm}$} & $D^{*}$ & 0.84 & 0.74 & 0.63 & 0.51 \\
\hline & $F^{*}$ & 0.79 & 1.07 & 1.18 & 1.23 \\
\hline & $W^{*}$ & 0.67 & 0.79 & 0.74 & 0.63 \\
\hline \multirow{3}{*}{$5.0 \mathrm{~mm}$} & $D^{*}$ & 0.80 & 0.70 & 0.59 & 0.48 \\
\hline & $F^{*}$ & 0.79 & 1.09 & 1.22 & 1.29 \\
\hline & $W^{*}$ & 0.63 & 0.76 & 0.72 & 0.62 \\
\hline
\end{tabular}

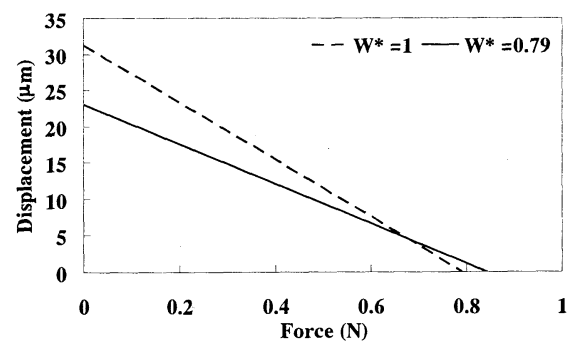

Fig. 7 Analytical force-displacement results of four-supported TAMPA (4 layered)

オース $F$ を支持部が理想的な点接触をしている場合 の值で以下のように正規化する.

$$
\begin{aligned}
& D^{*}=\frac{D}{D_{p}} \\
& F^{*}=\frac{F}{F_{p}}
\end{aligned}
$$

$D_{p}, F_{p}$ はそれぞれ，支持部が理想的な点接触をして いる場合の自由変位とブロッキングフォースである. 厚さ $0.4 \mathrm{~mm}$ のバイモルフ型圧電素子 4 層の場合,

解析により $D_{p}=31.2 \mu \mathrm{m}, F_{p}=0.79 \mathrm{~N}$ が得られる. 式

（1），（2）から，正規化された仕事 $W^{*}$ は

$$
W^{*}=D^{*} \times F^{*}
$$

となる. 解析を行った 16 パターンの $D^{*}, F^{*}, W^{*}$ の值を表 3 にまとめる.

表 3 より，支持部のサイズによって変位と力のバ ランスが異なり, 変位に優れた形状と力に優れた形 状とがあることが分かる. 支持部分の面積が小さい ほど変位に優れ，大きいほど力に優れるといえる. その中でも $W^{*}$ の最も高い $p=1.0 \mathrm{~mm}, q=4.0 \mathrm{~mm}$ の

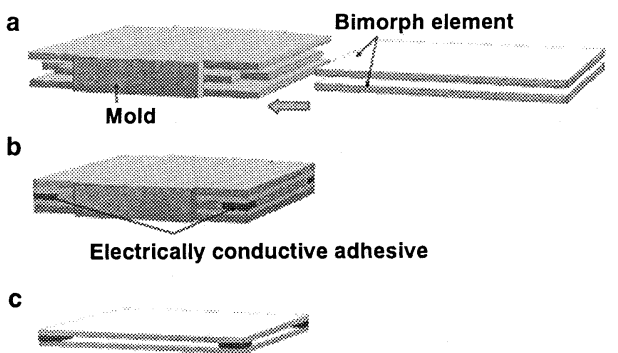

d

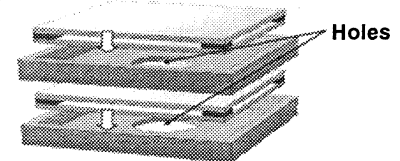

e

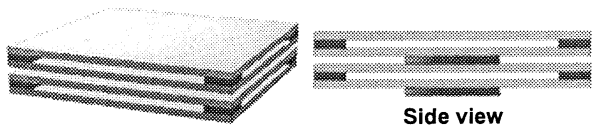

Fig. 8 Fabrication process of four-supported TAMPA

形状が最も効率よく動作しているといえる．理想的 な点接触をしている場合 $\left(W^{*}=1\right)$ と， $W^{*}$ の最も高 い場合 $\left(W^{*}=0.79\right)$ の変位と力の関係を図 7 に示す. 点接触に比べ, 変位が減少した分, 力が増加したア クチュエータとなっている.

\section{4. 製作方法}

前節で設計した形状の支持部を持つ TAMPAを，イ ンクジェット式ワックス造形によるモールドを用いて 作製する.インクジェット式ワックス造形とは, 溶融し たワックスを一層ずつ印刷していくことで立体構造物 を作製する造形手法であり, 精密に任意の立体構造物を 作製できる.また，この造形物はアセトンやエタノール 等で溶解させ容易に除去することができる. 造形装置は 
Pattern Master (Solidscape Inc.)を用いた。また，積層ピツ チは $0.038 \mathrm{~mm}$ とした.

インクジェット式ワックス造形によるモールドを用 いた TAMPA の作製手順を図 8 に示す。 バイモルフ型 圧電素子は 2 枚の圧電セラミックス (PZT C-6, Fuji Ceramics Corporation) を導電性接着剤（ドータイト XA-910, Fujikura Kasei Co., Ltd.）で接着して作製した. まず, 2 枚のバイモルフ型圧電素子が 4 点支持で組み合 わさったパーツからら作製する. 4 点支持部用のモ一ルド にバイモルフ型圧電素子を組み込み（図 8-a），支持部 となる空間に導電性接着剤を塗りこむ（図 8-b），支持 部に導電性を持たせるのは, 向か心冾う面を導通させる ことて配線の手間を減らすためである. 導電性接着剤を 硬化させ, モールドを除去すれば4 点支持で組み合わさ れたパーツが作製される（図 8-c）。このパーツを，中 心支持部用のモールドと交互に積層寸る（図 8-d）。こ のとき, モールドの穴に導電性接着剤を塗りこむ. 再び 導電性接着剤を硬化させ, モ一ルドを除去すれば4 点支 持構造のTAMPAが作製される（図8-e）。最後に，層

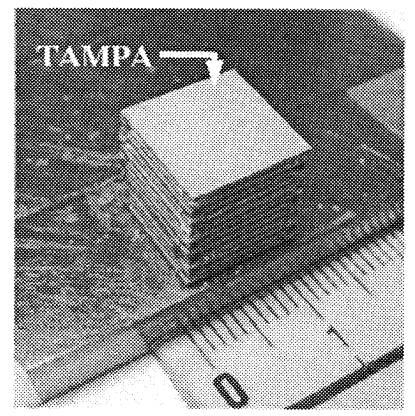

Fig. 9 Photograph of four-supported TAMPA

(12 layered)

(a)

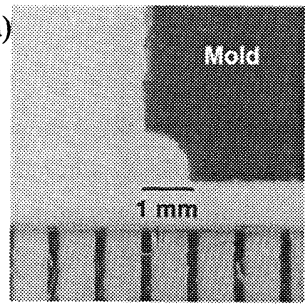

(c)
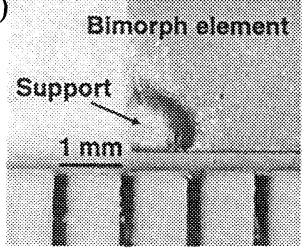

Fig. 10 Photograph of mold and support: (a) mold for corner support, (b) mold for center support, (c) corner support, (d) center support
の隙間から配線を通せば完成する.

\section{5. 実験}

プロトタイプとして, 12 層のTAMPAを作製した(図 9）.サイズは $10 \times 10 \times 10 \mathrm{~mm}$ となった. 支持部分の形状 を図 10 に示寸。図 10 (a), (b)はインクジェット式ワッ クス造形によるモールドの，それぞれ4 点支持部，中心 支持部である.この部分に導電性接着昘を塗りこみ，硬 化させるとそれぞれ図 10 (c), (d)のようになる. 前節で 設計した形状の支持部が作製できていることが分かる.

プロトタイプ (Experiment)，有限要素解析によるシ ミュレーション（Simulation），およひ導電性テープに より作製されたTAMPA（Old style）の変位と力の関係 を図 11 に示す. す心゙て，バイモルフ型圧電素子は 12 層である．作製したプロトタイプは $65 \mu \mathrm{m}$ の変位と 1.1 $\mathrm{N}$ の力を発生させた. 実験結果はシミュレーション結果 と良く一致しており，設計どおりの TAMPA が作製で きているといえる. また，導電性テープにより作製され た 2 辺支持の TAMPA よりも性能の向上が見られ，仕 事 $W^{*}$ で比較すると約 1.5 倍であった．これは，先の解 析結果で示したとおり，4点支持にすることにより，変

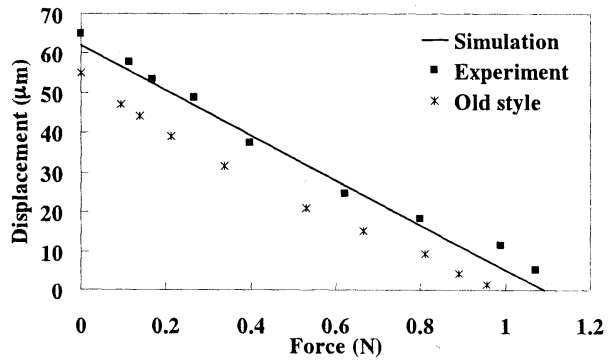

Fig. 11 Force-displacement results of four-supported TAMPA (12 layered)

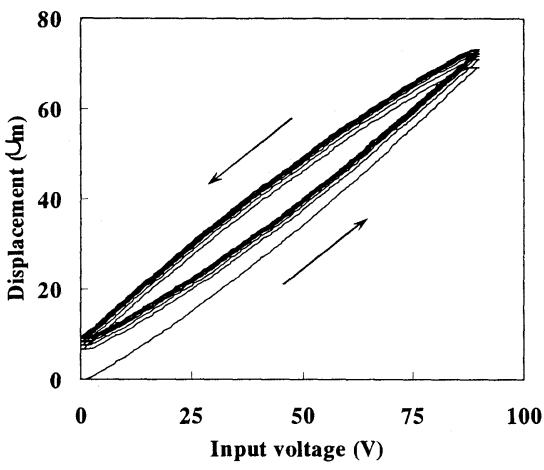

Fig. 12 Displacement-input voltage results of four-supported TAMPA (12 layered) 


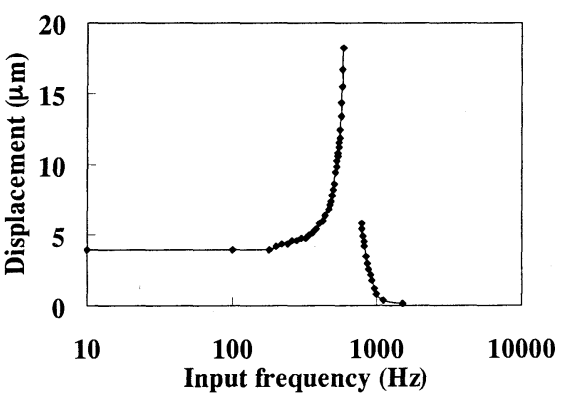

Fig. 13 Displacement-input frequency results of four-supported TAMPA (12 layered)

位と力が共に向上したためと考えられる. 支持部にかか る圧力は，力が最大 $(1.1 \mathrm{~N})$ の場合でも，4点支持部で $312 \mathrm{kPa}$ 程度，中心支持部で $87 \mathrm{kPa}$ 程度であり，支持部 の強度は十分であったといえる. 図 12 に入力電圧と変 位の関係を示す.本アクチュエータはヒステリシスとド リフトを有しており,これらの低减と制御に関しては今 後の課題とする. 図 13 に入力周波数と変位の関係を示 す. 人力電生は $20 \mathrm{~V}_{\mathrm{pp}}$ である. 共振点付近では変位が 乱れ，測定することができなかった（590～780 Hz）. 共振周波数は $600 \mathrm{~Hz}$ 程度であると思われる. 共振点付 近で変位が乱れるのは, TAMPAが板状のバイモルフ型 圧電素子を積層した構造であるため, 1 枚 1 枚の縦方向 と横方向の変形が入り混じり, 全体の変形が不安定にな るためであると考えられる. したがって, 本アクチュエ 一タを安定して使用できるのは $400 \mathrm{~Hz}$ 程度までである.

\section{6. 結 言}

本論文では，変位と力を両立したテーラーメード型 積層圧電アクチュエータ（TAMPA）の最適支持構造を 提案した. まず, バイモルフ型圧電素子が板状であるこ とから，支持を 2 辺支持から 4 点支持八変更した. この ことから，TAMPAの全体の構造は，板の中心支持と 4 点支持を繰り返し積層した構造とした. 次に，4点支持 を適用した TAMPA の性能を有限要素解析により評価 した. 支持部の面積の違いによる 16 パターンの解析結 果から, 支持部分の面積が小さいほど変位に優れ, 大き いほど力に優れるということが分かった. その中で, ア クチュエータの為す仕事が最も大きいサイズと形状を 決定した.このとき為す仕事は, 理想的な点接触構造の 場合の 0.79 倍であった. 最後にプロトタイプを作製し, その性能を評価した. 設計した支持形状は, 作製にイク ジェット式ワックス造形によるモールドを利用するこ とで実現した. 評価結果は解析結果と良く一致しており， 設計の有効性が確認された.
本研究により, 支持部の形状がアクチュエータ性能 に大きな影響を与えることが分かった. 任意の性能を得 ることや，エネルギ一効率を上げるためには，支持部の 岡性や厚みなど, さらなる解析が必要である. また, 強 度に関しても, 支持部のサイズや物性に依存寸るため検 討が必要である. さらに今後は, 本アクチュエータの小 型化と生産性の向上を行う予定である.

(1) K. Uchino, Piezoelectric/Electrostrictive Actuators, Morikita Publishing Co., Tokyo (1986). [in Japanese]

(2) G. H. Haertling, Ferroelectric Ceramics: History and Technology, Journal of the American Ceramic Society, Vol. 82 (1999), pp. 797-818.

(3) E. Furukawa, M. Mizuno and T. Doi, Development of a Flexure-Hinged Translation Mechanism Driven by Two Piezoelectric Stacks, JSME International Journal, Series C, Vol. 38 (1995), pp. 743-748.

(4) D. K. Samak and I. Chopra, Design of High Force, High Displacement Actuators for Helicopter Rotors, Smart Materials Structures, Vol. 5, no. 1 (1996), pp. 58-67.

(5) K. Onitsuka, A. Dogan, J. F. Tressler, Q. Xu, S. Yoshikawa, and R. E. Newnham, Metal-Ceramic Composite Transducer, The "Moonie", Journal of Intelligent Material Systems and Structures, Vol. 6 (1995), pp. 447-455.

(6) A. Dogan, K. Uchino, and R. E. Newnham, Composite Piezoelectric Transducer with Truncated Conical Endcaps "Cymbal", IEEE Transactions on Ultrasonics, Ferroelectrics, and Frequency Control, Vol. 44 (1997), pp. 597-605.

(7) M. R. Steel, F. Harrison and P. G. Harper, The Piezoelectric Bimorph: An Experimental and Theoretical Study of Its Quasistatic Response, Journal of Physics D: Applied Physics, Vol. 11 (1978), pp. 979-989.

(8) G. H. Haertling, Rainbow Ceramics-A New Type of Ultra-High-Displacement Actuator, American Ceramic Society Bulletin, Vol. 73 (1994), pp. 93-96.

(9) K. M. Mossi, G. V. Shelby and R. G. Bryant, Thin-layer Composite Unimorph Ferroelectric Driver and Sensor Properties, Materials Lett. Vol. 35 (1998), pp. 39-49.

(10) J. D. Ervin and D. Brei, Recurve Piezoelectric Strain Amplifying Actuator Architecture, IEEE/ASME Trans. Mechatron., Vol. 3 (1998), pp. 293-301.

(11) J. D. Ervin and D. Brei, Dynamic Behavior of Piezoelectric Recurve Actuation Architectures, $J$. Vib. Acoust., Vol. 126 (2004), pp. 37-46.

(12) K. Motoo, N. Toda, F. Arai and T. Fukuda, High Performance Multilayer Piezoelectric Actuator using Bimorph Type Piezoelectric Element, ACTUATOR 2006, pp. 499-502.

(13) K. Motoo, N. Toda, F. Arai, T. Fukuda, T. Matsuno, K. Kikuta, and S. Hirano, Tailor-made Multilayer Piezoelectric Actuator Having Large Displacements and Forces, Transactions of the Japan Society of Mechanical Engineers, Series C, Vol.72 (2006), pp. 3302-3309. [in Japanese] 